A solution, containing more chlorine than No. 9, was cooled to $-72^{\circ}$ with no separation of solid. Several samples, including No. 6, were cooled to $-70^{\circ}$ and in no case was there complete solidification. From Nos. 4 and 8 a portion of solid was removed by means of a glass scoop, rinsed with petroleum ether cooled to $-70^{\circ}$, transferred to alkali, and the ratio $\mathrm{As}: \mathrm{Cl}$ determined. In the material obtained from No. 4 it was $I: 3.3$; from No. 8, I: 4. The outside of the mass of crystals was white after rinsing in each case and, in our opinion, they were arsenic trichloride contaminated by mother-liquor containing an excess of chlorine.

Lewis INSTItUTE, ChICAGo, March, I904.

[CONTRIBUTION FRoM THE HAVEMEYer LABORATORIES OF COLUMbIA UNIVERSITY No. 95.]

ON THE COMBINATION OF A SOLVENT WITH THE IONS.

(PREIIMINARY PAPER.)

BY J. Livingston R. MORGaN AND C. W. RaNolt.

Receired April 1, 2904.

As a result of the electrolysis of a solution of silver nitrate and pyridine in water, a loss of pyridine has been observed at the anode and a corresponding gain of pyridine at the cathode. By similar experiments with cupric nitrate and water, dissolved in alcohol (which, owing to experimental difficulties, are to be regarded only as preliminary) the quantity of water has been found to decrease at the anode and to increase at the cathode.

These experiments indicate that in such mixed solutions some of the ions combine with one of the solvents to form complex ions, which go through the solution and break up at the electrodes. The silver is accompanied by pyridine; the copper by water. If the negative ions are also so combined, the changes in concentration observed give only the differences between the amounts carried by the positive and by the negative ions.

The formation of such ionic complexes in mixed solvents leads to the conclusion that they also exist in solutions in one solvent; or, in other words, when a substance ionizes in going into solution, the ions, one or both, attract a certain amount of the solvent and form complex ions with it. 
Applying the law of mass action to an equilibrium in which these complexes of ions and solvent are present, very striking results are obtained, as will be observed by a glance at a few of the possible cases:

I. Complex ions are formed from the simple ions, but neither condenses.

If $\mathrm{MA}$ is the salt and $\mathrm{S}$ the solvent, we have

$$
\mathrm{MA}+(x+y+z) \mathrm{S}=\mathrm{M} \cdot \dot{+} \mathrm{S}+\mathrm{A} \cdot \bar{y} \mathrm{~S}+z \mathrm{~S},
$$

and assuming $\mathrm{C}_{s}$ as the concentration (in moles per liter) of undissociated portion, and $\mathrm{C}_{i}$ that of one of the ions, then, if $x$ and $y$ are small as compared with $z$,

$$
\mathrm{C}_{t}^{2}=\text { constant }
$$

i. $e$., Ostwald's dilution law, as would be obtained if there were no combination.

II. Two ions of one kind wnite with the solvent to form one complex ion; i. e., one ion condenses, the other does not.

$$
2 \mathrm{MA}+(x+2 y+z) \mathrm{S}=\mathrm{M}_{2}^{+} \cdot \dot{x} \mathrm{~S}+2(\overline{\mathrm{A}} \cdot \overline{\mathrm{y}} \mathrm{S})+z \mathrm{~S},
$$

where $y$ may or may not be zero. We have then

$$
\frac{\mathrm{C}_{i}\left(2 \mathrm{C}_{i}\right)^{2}}{\mathrm{C}_{s}^{2}}=4 \frac{\mathrm{C}_{i}^{3}}{\mathrm{C}_{s}^{2}}=\text { constant ; }
$$

i. e., van't Hoff's (form of Rudolphi's ${ }^{2}$ ) empirical dilution law, which holds for strong electrolytes, but which has never been satisfactorily accounted for.

III. Both ions condense.

If $\mathrm{M}$ is bivalent,

$$
2 \mathrm{MA}_{2}+(x+2 y+z) \mathrm{S}=\overrightarrow{\mathrm{M}_{2}} \cdot \overrightarrow{+} \cdot \overrightarrow{\mathrm{S}}+2 \overrightarrow{\mathrm{A}_{2}} \cdot \vec{y} \mathrm{~S}+z \mathrm{~S},
$$

and we have the van't Hoff form again as in II.

The value of $n$ in the general dilution law,

$$
\frac{\mathrm{C}_{i}^{n}}{\mathrm{C}_{s}}=\text { constant, }{ }^{3}
$$

then depends upon the ionic combinations which are present in the solution. The slight variation observed in the value of $n$ for

1 Ztschr. phys. Chem., 18, 300 (:895).

2 Ibid., 17, $3^{85}$ (1895).

Bancroft: Ibid., 31, 188 (1899). 
any one substance is probably due to the further dissociation of the complex ion. which may even become complete, or to the presence of small quantities of complex ions of different form, or, in concentrated solutions, to the variation in the amount of free solvent available. To this breaking-down of the complex ions is probably due also the variation in the speed of migration of the ions with the dilution. The existence of such complexes also accords with the presence of solvent of crystallization in many salts.

It will be observed that this is simply a modification of the ionic theory and takes nothing away from it. In fact, it appears to condition only those portions of the theory which have hitherto failed to hold.

Work is being continued upon these lines in this laboratory, and will be reported upon as soon as possible.

LABORATORY OF Phystcal Chemistry, March 3r, 1904 .

\author{
[CONTRIBUtion FROM THE BUREAT OF Chemistry, U. S. DePT. OF \\ AGRICUL,TURE, No. 54.]
}

\title{
COMPARISON OF METHODS FOR THE ESTIMATION OF SOIL ACIDITY.
}

BX F. P. VeITCR.

Received April 7, 1904.

WITHIN the past year and a half two new methods have been proposed for the estimation of the acidity of soils. These are the sodium chloride method devised by Hopkins, Pettit and Knox, ${ }^{1}$ and the lime-water method devised by the writer. ${ }^{2}$

Considerable work has been done with both these methods during the past year, and many of the data obtained have been incorporated in the report of the referee on soils and presented to the Association of Official Agricultural Chemists at the twentieth annual meeting.

Broadly speaking, no more striking proof of the importance of maintaining an alkaline reaction of the soil is needed than is furnished by those soils which have become famous for their

1 Bull. 73, Bureau of Chemistry, U. S. Dept. of Agr.

2 This Journal, a4, 1 I 20 (1902). 